Notas y reseñas 

Acta Poetica $33 \cdot 2$

JULIO-DICIEMBRE

$2012(211-221)$

\section{Crítica de la edición crítica. Respuesta a Margit Frenk}

Un reciente artículo de mi admirada Margit Frenk contiene implicaciones teóricas dignas de estudio y alusiones personales merecedoras de respuesta. Se titula "Un poema en movimiento: La más bella niña, de Luis de Góngora". " Comienza con reflexiones acerca de la función de la memoria en la literatura antigua, para lo cual se apoya sobre todo en el Éloge de la variante de Bernard Cerquiglini (Paris, Seuil, 1989). Pone así de relieve la constante reescritura de los textos, su continua variación "en un estado de fluidez parecido al de la poesía popular" (p. 107), materia en la que la profesora Frenk es indudable autoridad, máxime cuando tal poesía se transmite a través de la música. En consecuencia, censura la concepción decimonónica y “escritocéntrica” de la actual ecdótica hispánica - como muestra la afirmación de Alberto Blecua, para quien la memoria es una "potencia nociva"y pasa a estudiar el caso del romancillo de Góngora. Según M. Frenk, “el romancero es un género consustancialmente cantado" (p. 110), por consiguiente Carreira, en su edición crítica, ${ }^{2}$ hace mal en no recordar que "varios de los testimonios utilizados son cancioneros polifónicos o traen cifras para tocar la guitarra y acompañar el canto" (pp.110-111). Esto último no se entiende, porque de los 94 romances de Góngora, Carreira sí indica, siempre al fin de cada prefacio, cuándo cada romance fue puesto en música. Aquí, concretamente, dice: “ $A j$ [es decir, el ms. da Ajuda] contiene una partitura anónima de este romance para tres voces y acompañamiento" (I, p. 183). Que el musicólogo Querol haya hecho la transcripción para dos tiples y tenor, aunque el ms. prescriba "a 4" (como señala en nota M. Frenk, p. 113), es problema en que no vamos a entrar, porque no es nuestra competencia. En

${ }^{1}$ Itzíar López Guil y Jenaro Talens (eds.), El espacio del poema. Teoría y práctica del discurso poético (Madrid: Biblioteca Nueva, 2011), pp. 105-117.

${ }^{2}$ Góngora, Romances, ed. crítica de A. Carreira, Barcelona: Quaderns Crema, 1998, 4 vols. 
la lista de testimonios dejamos claro que para los musicales íbamos a usar el Cancionero musical de Góngora, de Miguel Querol (Barcelona, 1975). $\mathrm{Si}$ en lugar de censurarnos errores que no hemos cometido, M. Frenk nos hubiera reprochado hacer caso de esos testimonios, que ella tanto aprecia, al componer nuestra edición, estaría mucho más cerca de la verdad, porque ahora se ve claro que no pertenecen a la transmisión textual de Góngora sino a su difusión, cosa muy distinta. Lo que encontramos en dicho Cancionero es la transcripción de los poemas gongorinos puestos en música, fruto de las pesquisas llevadas a cabo por Querol. En total son 38, de los cuales uno, el romance "Guarda corderos, zagala", se encuentra en tres mss., con lo que la suma de transcripciones llega a 40. En ellos solo hay dos modalidades: romances (26) y letrillas (11 más un poema en seguidillas), de los que se deben descontar 2 letrillas y 12 romances simplemente atribuidos, alguno por el propio Querol. Góngora, que sepamos, compuso 94 romances y 59 letrillas, que suman 153 poemas en esos géneros; de ellos, hay música para 24. Dejando a un lado las letrillas, veremos que de los 94 romances auténticos, 14 han sido puestos en música, lo cual no alcanza al $15 \%$, un porcentaje todavía apreciable, pero que no permite afirmar que el romancero de Góngora sea un género "consustancialmente cantado", y menos aún si se atiende al número de versos. Pero atengámonos a lo que hay, y veamos en qué consiste la transmisión por vía musical. "Ciego que apuntas y atinas" tiene 50 versos en el ms. Chacón (Ch); en la versión musicada por Hidalgo cuenta 25. "La más bella niña" tiene 60 en Ch; en el ms. musical Ajuda, cuenta 22. Lo contrario sucede con "Las redes sobre el arena", de solo 8 versos en Ch, ampliados hasta 26 en el ms. Ajuda. "Sin Leda y sin esperanza" tiene 36 versos en Ch; 10 menos en el ms. Ajuda. "Las aguas de Carrión" tiene 40 versos en Ch, la mitad en el ms. Ajuda; de su fidelidad da idea su primer verso, "Las redes al sol tendidas" que pretende reproducir el v. 21, "Las redes al sol tendía", de la versión canónica, así como el hecho de que el estribillo musical conste de cuatro versos, cuando el original consta de dos. No vamos a examinar todos los casos, porque no hace falta; solo uno extremo: el romance "Ojos eran fugitivos", que cuenta 80 versos en $\mathrm{Ch}$, se reduce a 8 en el ms. de $\mathrm{N}^{\mathrm{a}}$ $\mathrm{S}^{\text {a }}$ de la Novena, es decir, a su décima parte. Como se ve, sin entrar en otras libertades y disparates que ofrecen las versiones musicales, ni con la mejor voluntad se las puede tener en cuenta para establecer un texto crítico; ya hemos reconocido que, si en algo peca nuestra edición, es en haber hecho caso de ellas. Tampoco habrá que recordar los frecuentes reproches a los músicos por hacer mangas y capirotes con los textos. Nos limitaremos a recordar uno, que M. Frenk conoce, sin duda, pero no trae a colación. Se trata del romance en que Pedro de Flores, editor del Ramillete de flores. Quarta, quinta y sexta 
parte de Flor de romances nueuos (Lisboa, 1593), responde a la acusación de los músicos ante el tribunal del Parnaso. He aquí un fragmento:

\author{
Procuré con mi sudor \\ y con inmenso trauajo, \\ juntar diuersos romances \\ que andauan descarriados, \\ y hize que de vn discurso \\ se viesse principio y cabo, \\ lo que el músico no haze, \\ pues medio desbaratado, \\ dexa vn romance perdido \\ diziendo que le da enfado... \\ Todos dixeron que sí \\ y que lo darán firmado, \\ y esto en presencia de todos \\ se proueyó en los estrados, \\ y mandan por su sentencia \\ que ninguno sea osado \\ tener de oy en adelante \\ mentirosos cartapacios, \\ y a los músicos condenan \\ que paguen lo processado, \\ y que no dexen jamás \\ el romance comen[ça]do
}

(ff. $7 v-8 v)$.

El "inmenso trabajo" que se tomó Pedro de Flores, y las acusaciones a los músicos de dejar estropeados los romances, junto con la escasez de transcripciones musicales conservadas en "mentirosos cartapacios", se compadece muy mal con lo de que el romancero nuevo sea un género "consustancialmente cantado", y menos aún con que semejante canturía, cuando se da, tenga algo que ver con la transmisión real de los textos. Ya Montesinos, en un artículo de hace 60 años, enumeró los lamentos de Pedro de Moncayo, Pedro de Flores y Sebastián Vélez de Guevara, respecto a cómo la música, que acercaba los romances a todos, "en ocasiones los malparaba de manera que sus mismos autores se negarían a reconocerlos". ${ }^{3}$ A M. Frenk le parece admirable la frase de Lope de Vega "No se obliga la memoria a las mismas palabras sino a las mismas

${ }^{3}$ J. F. Montesinos, “Algunos problemas del Romancero nuevo" (1953), ap. Ensayos $y$ estudios de Literatura española, ed. de J. H. Silverman (México: De Andrea, 1959), p. 78. Algo después remacha: "Desde que los primeros compiladores, que se profesaban humanistas, siquiera fuesen de los más modestos, acometieron la empresa de reunir es- 
sentencias" (p. 107), pero no son menos significativas las quejas de cómo la tal memoria dejó tan estragadas sus comedias que, según él mismo dice, le sería mejor escribirlas de nuevo que enmendarlas. ${ }^{4}$

Describe M. Frenk "cómo procedió Antonio Carreira en su reciente edición crítica [...]: elige en cada caso una sola fuente y, ateniéndose totalmente a ella, presenta un texto que considera ideal [...] y en seguida construye, con todas las demás versiones encontradas, un impresionante aparato de variantes" (p. 110). Lo que esto significa es sencillamente que la edición no es neolachmanniana, como tampoco lo son las de la poesía de Quevedo o de los Argensola publicadas por José Manuel Blecua, la de las Letrillas y Sonetos de Góngora debidas respectivamente a Robert Jammes y Biruté Ciplijauskaité. El método de Lachmann, o que se le suele atribuir, es muy útil para unas cosas, pero totalmente inaplicable a la poesía del Siglo de Oro; prueba de ello es que en la mayoría de sus ediciones no hay, porque no puede haber, un stemma válido que dé filiación de los testimonios, casi todos de rama baja. Si se quiere bautizar de alguna manera el método de estos filólogos, habría que llamarle neobédierista, puesto que, en efecto, reproducen siempre un testimonio de época, considerado más limpio y maduro, relegando al aparato crítico los demás, o dando ejemplos de ellos en letra pequeña, como hace Blecua y, de vez en cuando, también Carreira. Que luego ese aparato sea muy abultado no es culpa del editor, y en nuestro caso no quedó más remedio que abreviar haciéndolo compacto. M. Frenk se fija en la versión de "La más bella niña" conservada en la Flor de varios romances nuevos, primera y segunda parte (Barcelona, Iayme Cendrat, 1591), f. $104 \mathrm{v}$, porque el estribillo del romance, "Dejadme llorar / orillas del mar", o "de la mar", presenta allí la variante "Dexadme llorar / orillas del amar", que según ella Carreira no recoge (p. 114). No es del todo exacto; en el aparato de los vv. 9-10 puede verse $f 2$, que representa ese libro, como uno de los testimonios que leen de la mar, lo que quiere decir que el editor interpretó del amar como una errata, de las muchas en que incurren las Flores, debido a que la regleta de separación se colocó en lugar indebido, después y no antes de la ele, las dos únicas veces que esa versión registra el estribillo. Sin salir de esa Flor de romances nuevos ni de los romances de Góngora, encontramos, en "Que se nos va la pascua, moças", esta cuarteta: "Mirad que quando pensáys / que hazen la

tos romances, aparecieron como enemigos declarados de músicos que, si difundían las composiciones que cantaban, también las envilecían de modo intolerable".

${ }^{4}$ Las dedicatorias de partes XIII-XX de Lope de Vega, ed. T. E. Case; en pp. 70-71, la de Santiago el Verde, donde está la frase citada. En la de La Arcadia, dice haber leído los traslados de un celebrado memorilla, y en ellos encontró "que para un verso mío, hay infinitos suyos, llenos de locuras, disparates e ignorancias" (p. 55). 
señal del alua / las campanas de la vida / es la que da y os desarman / de vuestro valor y lustre, / de vuestro donayre y gracia" (f. 113). "Es la que da" hace cierto sentido, pero Góngora escribió una lectio difficilior: "es la queda", por ello viene a continuación el desarme, obligatorio tras el toque de queda; la regleta separó indebidamente que y $d a$. En el romance "Aquí entre la verde juncia", también de Góngora, se dice: "Descanse entre tanto el arco / del acuerdo que le aflige" (f. 118). La lectura correcta es "de la cuerda que lo aflige"; la regleta de separación, una vez más, se colocó en lugar erróneo; no es del acuerdo, sino de la cuerda; no hay ningún acuerdo capaz de afligir un arco. En "Servía en Orán al rey", asimismo gongorino, la amada del español le dice: "Vestíos y salid apriessa, / que el general os aguarda: / yo os hago a vos muchas obras / y vos a él mucha falta" (f. 141v). Lo que Góngora escribió no es "muchas obras" sino "mucha sobra", sintagma que contrasta con "mucha falta" en el verso siguiente; de nuevo la regleta se colocó en lugar inadecuado.

Si esto sucede en tres ocasiones, y las tres de Góngora, en la Flor de 1591, nada tiene de extraño que haya sucedido también en el estribillo de "La más bella niña", produciendo la extraña variante "orillas del amar" que ninguna edición posterior recoge, pequeño dato que M. Frenk omite. He aquí como la interpreta: "La jovencita recién casada y ya viuda estaba apenas viviendo el sabroso oficio del dulce mirar, y eran solo los ojos de él los que la desvelaban: se encontraba realmente a las orillas del amar" (p. 114). Una hermosa novela cuyo único fallo es admitir para un estribillo del s. Xvi una metáfora vanguardista. Ese amar con orillas es aún más moderno que el cantarcillo que puso Rulfo en Pedro Páramo: "Mi novia me dio un pañuelo / con orillas de llorar", 5 pues al fin un pañuelo puede tener huellas de llanto en sus bordes, mientras que el amar, difícilmente.

El elogio de la variante puede llevar muy lejos, hasta convertirse en elogio de la errata. Volvamos al comienzo del romancillo: "La más bella niña / de nuestro lugar / hoy es viuda y sola / y ayer por casar / viendo que sus ojos / a la guerra van / a su madre dize / que escuche su mal" (Flor de varios romances nиеиоs, 1591, f. 104v). En los buenos testimonios, no solo Chacón, sino una docena de mss. integri independientes, más la ed. Vicuña, cuyo texto se terminó de recopilar hacia 1620, el v. 2 lee: "hoy viuda y sola", como frase nominal que sirve de aposición al sujeto, mientras que el v. 8 lee "que escucha su mal", oración de relativo y no completiva. Lo que la moza dice a la madre no es que escuche su mal, sino el lamento subsiguiente, precedido de un estribillo que no hay por qué poner en su boca. A pesar de ello, M. Frenk considera la

${ }^{5}$ Juan Rulfo, Pedro Páramo, ed. de J.C. González Boixo, Madrid: Cátedra, 1989, p. 113. 
variante que escuche "más natural y fluida que la otra" (p. 114); sin embargo, no es nada natural para una hija pedir a su madre que escuche sus cuitas, algo a lo que siempre está dispuesta. De igual modo cree "tan válido hoy viuda como hoy es viuda", cosa incierta; "hoy viuda" es una imagen, mientras que "hoy es viuda" constituye una falsedad, ya que la joven aún no ha enviudado, y supone también una falta de sintaxis porque el verbo es liga mal con sola. No contenta con eso, nuestra investigadora se fija en las dos últimas coplas (convertidas en intermedias en la Flor de 1591), donde la moza desea que las noches pasen aprisa con estas palabras: "Váyanse y no vean / tanta soledad, / después que en mi lecho / sobra la mitad" (vv. 57-58), lo que tiene un sentido pleno y meridiano. Pues bien; M. Frenk rescata del aparato crítico dos mss. deleznables que leen no "sobra", sino "falta la mitad", e intenta defender la variante con este argumento: "Se diría un error, pero no lo es: la mitad le sobra al lecho y le falta a la muchacha". ¿Le falta la misma mitad que le sobra? No sabemos. La novela sigue su curso, y es lástima que no conozcamos el final.

De todo lo dicho, lo único que se puede concluir es que los testimonios musicales, desde muy antiguo, son muy poco aprovechables, por la sencilla razón de que los músicos hacen prevalecer la música sobre la fidelidad al texto, como hizo en nuestro tiempo Falla con el pasaje de maese Pedro. El maestro Risco puso música a villancicos de Góngora; si se conservara, habría que ver qué tal quedaron. Y la oralidad del romancero, incluida la del viejo, estuvo siempre muy reforzada y retroalimentada por la escritura, cosa que las teorías neorrománticas han tendido a silenciar. El escritocentrismo, como su antónimo, el oralcentrismo, son solo constructos mentales para pasar el rato. La anécdota de Pacheco sobre la feliz memoria de Baltasar del Alcázar, muy significativa según M. Frenk (p. 109), solo prueba algo que siempre fue normal: que un poeta sepa de coro sus propios versos. Y la otra, que se ha alegado alguna vez, relativa a un soneto de Góngora en un manuscrito cuyo amanuense, después de copiar los cuartetos, escribe "Los tercetos no me acuerdo", demuestra solo eso: que sabía los cuartetos pero no los tercetos, es decir, que su memoria no era tan feliz. ${ }^{6}$ De hecho, quienes sí la tenían buena serían los menos inclinados a poner por escrito lo que recordaban. Dejando aparte los cantarcillos populares recogidos por la propia M. Frenk, o romances de dicción simple como los

${ }^{6}$ Se trata del ms. Papeles diversos (sueltos, en p. 43) de Rodríguez-Moñino, consultado por Biruté Ciplijauskaité. Cfr. su edición de los Sonetos de Góngora (Madison, Wisconsin, The Hispanic Seminary of Medieval Studies, 1981), p. 103. No se ve en la anécdota base para deducir "cómo se copiaban muchos poemas", según hace la editora. La primera mención del soneto incompleto la hizo el propio Rodríguez-Moñino en Poesía y Cancioneros (siglo XVI) (Madrid-Valencia: Soler, 1968), pp. 26-29. 
de Delgadina, Gerineldo y otros por el estilo, nos faltan pruebas de que en la transmisión de la poesía culta interviniese la memoria de manera decisiva, y la prueba compete a quien afirma; mientras no aparezca, los demás haremos bien en mantener nuestro escepticismo. Con las jácaras de Quevedo ha sucedido algo similar; los quevedistas afirman que se cantaron mucho, y en el teatro; hasta la fecha nadie ha encontrado la partitura ni tampoco testimonio de que así fuera.

Para terminar con este asunto, es forzoso decir que en nuestro prefacio a "La más bella niña" hablamos de sus versiones primitivas, reelaboradas en la del ms. Chacón, y transcribimos la conservada antes de la guerra civil en el ms. del Centro de Estudios Históricos de Madrid (CEH), así como la vuelta a lo divino de Mateo Fernández Navarro. Lo que no hicimos es discutir un excelente artículo, que M. Frenk no menciona, de Bruce W. Wardropper titulado así, "La más bella niña", y publicado en 1966. Y no lo discutimos porque no era el lugar adecuado, como sí lo hubiera sido el trabajo de M. Frenk. Para Wardropper, el poemilla de Góngora se elaboró en tres fases; la primera sería la versión incluida en la Flor de varios romances nueuos, de Pedro de Moncayo, impresa en Huesca, 1589; segunda, la representada por el ms. perdido CEH transcrito por Torner; y la tercera, conservada en el ms. Chacón. Wardropper comete un lapsus menor cuando dice que parte del texto de Moncayo, "in the form in which it was printed in the Romancero general", porque el texto de 1589 no es el que pasó al Romancero general, sino el de la Flor de 1591, edición también atribuida a Moncayo, aunque ya no impresa en Huesca sino en Barcelona. ${ }^{7}$ La versión de 1589 presenta tres estrofas, o secuencias — como prefiere M. Frenk-, y al comienzo enuncia el estribillo anisosilábico que paradójicamente ya no se repite, y que Wardropper tiende a creer popular, aunque no se ha encontrado en texto anterior a la fecha asignada por Chacón al romancillo: 1580. Nuestro prefacio decía que el poema está trunco en esa Flor de 1589, por una razón gramatical: sus dos últimas cuartetas empiezan con una conjunción causal de la que no se deriva nada: "Pues me disteys, madre, / en tan tierna edad, / tan corto el plazer / y tan largo el pesar, / y me captiuasteys / de quien hoy se va / y lleua las llaues / de mi libertad". Tras estos versos figura la palabra: Fin; ni estribillo ni consecuencia. A nuestro juicio, no es posible que el Góngora de 19 años a quien se encargó la canción que figura al frente de la versión española

7 “La más bella niña was first published in Pedro de Moncayo's anthology, the Flor de varios romances nuevos y Canciones, which appeared in Huesca in 1589. The same text was incorporated into the Romancero general of 1600, as a result of which it enjoyed an enormous popularity", Bruce W. Wardropper, "La más bella niña", Studies in Philology, LXIII (Chapel Hill, N. C., 1966), p. 661. 
de Os Lusiadas, o que escribió piezas magistrales como "Hermana Marica", cometiera semejante torpeza. Y tampoco vamos a culpar aquí a la memoria, sino, una vez más, a los "cartapacios mentirosos" de los que tenemos sobradas muestras, sin que valga la pena hacer cábalas para averiguar por qué la mayoría de sus textos están deturpados. Los colectores de cancioneros misceláneos no eran filólogos, sino que copiaban o daban a copiar lo que les parecía útil según les llegaba después de numerosos traslados cada vez menos fieles; la atención o el descuido con que se han elaborado tales cartapacios recorren todos los grados de la escala.

Sea como fuere, la versión de 1591, que presenta dos secuencias nuevas de ocho versos en lugar de la tercera de 1589 , es la que interesa a M. Frenk, y la que Wardropper y Carreira consideran primitiva. Nuestro prefacio descarta que la del ms. CeH sea de Góngora por su carácter reiterativo. De hecho el mismo Wardropper ve la dificultad cuando afirma que "the Centro text must be, not a retouching of the original, but another effort to tame the same poetic material. Góngora abandons the method of apparent simplicity for that of rhetorical, artistic construction" (p. 662). Pero la "artistic construction" no se ve por ningún sitio: el lamento de la moza se prolonga en veintitantos versos sin añadir nada nuevo a lo ya dicho. Antes que intento de Góngora, la versión de ese manuscrito suena a glosa o rapsodia hecha por algún espontáneo a partir de las primeras coplas del romancillo, como si quisiera arreglar precisamente la versión truncada de 1589. En cambio, sí nos parece acertado lo que Wardropper descubre que hace Góngora con el poema, tal como lo transmiten los testimonios más autorizados, incluida la edición de Vicuña (lo cual indica que adquirió su forma final mucho antes del ms. Chacón): "He eliminates defects attributable to his youthful inexperience; he embodies a few details which please him from the second attempt; he reorders the strophes, adding to them one which is completely new" (p. 662). Por fin, entre las dos tendencias popular y culta en que se mueve el poema, Góngora muestra inclinarse por la segunda al suprimir todas o casi todas las huellas de las tradiciones folclóricas o de cancionero visibles en las versiones más antiguas (p. 672). En resumen, "each change can be explained by the reflection, the care, the search for perfection which characterize Góngora's mature work" (p. 676). M. Frenk cree que todas las versiones valiosas deberían estar al alcance del lector en un corpus electrónico relacional (p. 117). Ahora bien, para ese viaje sobraban las alforjas filológicas, porque lo único que se necesita son paleógrafos capaces de copiar sin error versiones manuscritas e impresas, o técnicos hábiles en manejar el scanner. Luego, lo que cada lector haga con ellas es otra cosa. Algo así sucede con los cancioneros manuscritos publicados por el equipo de Labrador-DiFranco, que hasta hoy han tenido mucho menos eco del esperable, el mismo que tendría el imagina- 
do corpus electrónico, y por igual motivo: porque constituyen un material en bruto donde resulta difícil orientarse, máxime con versiones manuscritas cuya fecha es casi siempre imposible de precisar.

El trabajo de M. Frenk, a nuestro juicio, tiene algunos puntos débiles: cree válidos para la poesía culta criterios que rigen en la popular, aplica a la poesía áurea conceptos más bien apropiados a la medieval, y atribuye a las versiones musicales un valor textual del que carecen. No obstante, sus palabras tienen el mérito de hacernos reflexionar sobre un hecho hasta ahora poco tratado, al menos en la filología hispana: la posibilidad o la conveniencia de hacer ediciones críticas en la poesía del Siglo de Oro. Por algo ese mismo rótulo no aparece en las debidas a filólogos competentes, como José Manuel Blecua o Biruté Ciplijauskaité, en las cuales hay aparato crítico, pero no texto que así pueda calificarse. La razón la hemos ya adelantado y es obvia: no se puede establecer tal texto cuando existen versiones válidas y próximas al autor. No se puede o no se debe, ya que el texto crítico, por definición, intenta restaurar un original perdido, y aquí no se ha perdido nada, si acaso una versión primitiva, más o menos rescatable a partir de testimonios tempranos las pocas veces que los hay. Y aun ahí es muy peligroso decretar que se trata de la versión genuina. Lo sucedido con "La más bella niña" lo demuestra a la perfección: el texto de 1589 es indefendible como original, y el único que tiene alguna posibilidad de reflejarlo es el de 1591, a pesar de que su final (v. 28 de la versión definitiva) es mucho más endeble, como lo son las otras variantes que hemos comentado. En la obra de Góngora tenemos algunos, pocos, testimonios tempranos, más o menos fiables: el más conocido, tras la edición de Robert Jammes, es el ms. Poesías de autores andaluces, que perteneció a Rodríguez Moñino, y que nos ha transmitido la versión primitiva de las Soledades, antes solo atisbada por Dámaso Alonso. Nosotros estudiamos hace años las fases de la décimaepitafio dedicada a Bonamí, según los testimonios disponibles. ${ }^{8}$ También de las décimas "De un monte en los senos donde" hemos localizado una versión acaso primitiva carente del estribillo que ostentan en los demás testimonios. El Cancionero de Gabriel de Peralta ( $\dagger$ 1625), ms. 4072 BNE, muy deteriorado, conserva cinco romances, alguno con fecha próxima a la dada por Chacón. Uno solo, "Dejad los libros ahora", se titula en él Querella de don Luis. 1591 años, y ofrece como remate una copla luego suprimida. Las demás variantes son de escasa entidad o perjudican el texto, como pasa en los otros. Sirva de ejemplo "Qué necio que era yo antaño", cuando el locutor dice que hace breves las noches de enero "por lo lacio y por lo tosco", o sea, leyendo libros latinos

8 "La décima de Góngora al conde de Saldaña (comentario de texto, y reflexiones sobre la enseñanza de la literatura en el Bachillerato)", RILCE, IX, 1993, pp. 170-193. 
y toscanos (v. 52); Peralta estropea el chiste al escribir "por lo labrado y lo tosco". Al margen de ello, omite veinte versos y en los demás da un orden distinto, fácil de reconstruir a partir del aparato de variantes. En cuanto al romance "Si sus mercedes me escuchan", en ese ms. contiene ocho coplas omitidas en la versión de $\mathrm{Ch}$, cuatro de las cuales figuran en el aparato, y las cuatro finales en nuestro prefacio. Por último, está el romance a santa Teresa, que se imprimió al año siguiente de ser compuesto para la fiesta cordobesa de la beatificación (1615), y luego fue retocado en el ms. Chacón. El lector es muy dueño de preferir una u otra versión, aunque los especialistas, ya desde antiguo, concuerden en que las finales, aun sin estar exentas de problemas, mejoran los textos. Baste recordar la anécdota transmitida por el Escrutinio respecto a la canción al sepulcro de Garcilaso, que, no habiendo merecido la aprobación de un amigo, fue totalmente rehecha por el poeta en el término de una tarde, de tal forma que "se excedió a sí mismo en ella" (Góngora, Obras completas, p. 1293).

Las ediciones habituales de nuestra poesía áurea, cuando tienen en cuenta todos los testimonios localizados, no son, pues, críticas en sentido estricto por las razones que acabamos de exponer; en realidad podrían designarse variorum editiones, puesto que intentan ilustrar los avatares de una transmisión en la que el poeta pudo tomar parte, pero también pudo no tomarla, salvo en los escasos manuscritos por él revisados. A los buscadores de primeras versiones les resultaría sin duda más cómodo tenerlas todas delante, en edición sinóptica (como la propuesta por Montesinos para un romance de Lope), ${ }^{9}$ o en reproducciones fotostáticas como las Fuentes del Romancero General que publicó RodríguezMoñino, en lugar de reconstruirlas trabajosamente a partir de un aparato crítico. En tal caso, para los romances gongorinos, en lugar de tres mil páginas tendríamos treinta mil o quién sabe cuántas, pero también sobre ellas sería mucho más fácil caer en disquisiciones que se pueden quebrar de sutiles al defender como adiáforas los deslices y ocurrencias de amanuenses e impresores.

Antonio CARreira

${ }^{9}$ Montesinos, Ensayos y estudios..., cit., p. 100. Se refiere al romance "Una estatua de Cupido". 


\section{REFERENCIAS}

CARreira, Antonio, "La décima de Góngora al conde de Saldaña (comentario de texto, y reflexiones sobre la enseñanza de la literatura en el Bachillerato)", RILCE, IX, 1993, 170-193. Incluido en Gongoremas, Barcelona, Península, 1998, 293-313.

CASE, T. E. (ed.), Las dedicatorias de partes XIII-XX de Lope de Vega, Valencia, Estudios de Hispanófila, 1975.

Frenk, Margit, "Un poema en movimiento: La más bella niña, de Luis de Góngora", en El espacio del poema. Teoría y práctica del discurso poético, Itzíar López Guil y Jenaro Talens (eds.), Madrid, Biblioteca Nueva, 2011, 105-117.

Góngora, Luis de, Obras completas, ed. Juan e Isabel Millé y Giménez, Madrid, M. Aguilar, 1932.

Góngora, Luis de, Romances, ed. crítica de Antonio Carreira, Barcelona, Quaderns Crema, 1998, 4 vols.

Góngora, Luis de, Sonetos, ed. de Biruté Ciplijauskaité, Madison, Wisconsin, Hispanic Seminary of Medieval Studies, 1981.

Montesinos, José F., Ensayos y estudios de Literatura española, J. H. Silverman (ed.), México, De Andrea, 1959, 109-124.

Rodríguez-Moñino, Antonio, Poesía y Cancioneros (Siglo XVI), Madrid/Valencia, Soler, 1968.

Rulfo, Juan, Pedro Páramo, J. C. González Boixo (ed.), Madrid, Cátedra, 1989.

WARDRopPer, Bruce W., "La más bella niña", Studies in Philology, 63, 1966, 661-676. 
